Asmaa A Abdulkadir

BDS, MSc (Asst. Lec.)

\section{Estimation of Acupressure Technique for Controlling of Gag Reflex of Prosthetic Patients}

Dept of Prosthetic Dentistry

College of Dentistry, University of Mosul

\begin{abstract}
الخلاصة

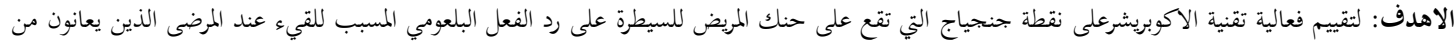

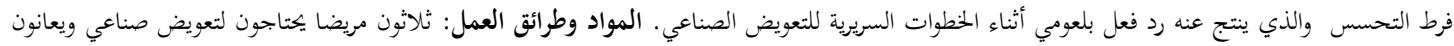

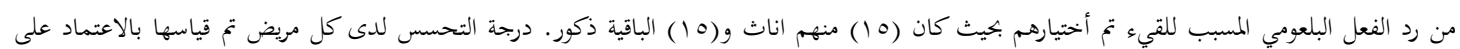

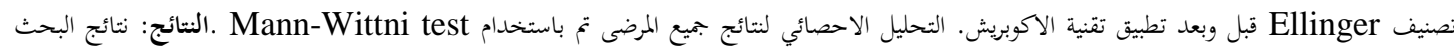

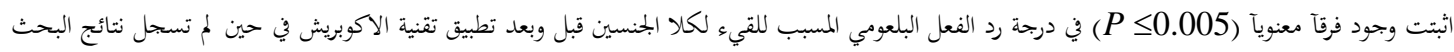

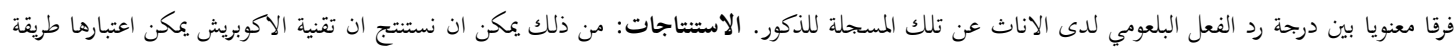

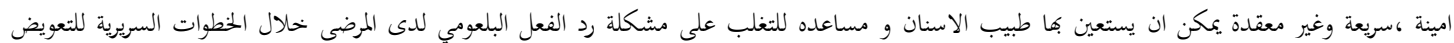

\title{
ABSTRACT
}

Aims: to evaluate the effectiveness of acupressure on Chengijiang (REN-24) point in controlling of gag reflex in hypersensitive male and female patients attending for prosthetic treatment. Materials and Methods: Thirty patients complaining from gag reflex during prosthetic treatment were selected. Fifteen were males and fifteen were females. The gag duration of each patient according to Ellinger classification was scored before and after acupressure. Statistical analysis to the results using Mann-Wittni test was done. Results: This study showed significant differences in scores of gagged patients (both males and females) before and after acupressure $(P<0.005)$; while there were no significant differences between scores of male patients after acupressure and scores of female patients after acupressure. Conclusion: Acupressure is a safe, quick, non invasive technique can be done by dentist or dental assistant to alleviate gag reflex of prosthetic patient.

Key words: acupressure, gag reflex.

Abdulkadir AA. Estimation of Acupressure Technique for Controlling of Gag Reflex of Prosthetic Patients. Al-Rafidain Dent J. 2013; 13(2): 340-345.

Received: $2 / 5 / 2012 \quad$ Sent to Referees: $7 / 5 / 2012$

Accepted for Publication: 14/6/2012

\section{INTRODUCTION}

Literatures identified 2 main categories of retching patients. The somatogenic group, in which gagging is induced by physical stimuli, and the psychogenic group, in which psychological stimuli are thought to initiate gagging. In addition to gag reflex induced by consumption of some drugs. ${ }^{(1)}$

For some dental patients, however, sever gagging can be elicited by the dentist's fingers or instruments contacting the oral mucosa or even by non tactile stimuli providing dental treatment for this challenging group can be a stressful experience for both patients and clinicians. ${ }^{(2)} \mathrm{A}$ number of prosthetic patients have a high gag reflex action when impressions are being taken. This causes a considerable inconvenience to the dentist as well as the patient. The resulting impressions are normally very poor and there is a reluctance to put either party through the experience again. This obviously leads to poorly fitting and poorly made prosthesis. ${ }^{(3)}$

There are many studies have been made to control or diminish gag reflex during dental treatment or during denture wearing such as swabbing patient's mouth with diluted cocaine or using distraction technique. ${ }^{(4)}$ Asking the patients to hold his breathe while the impression tray is checked. ${ }^{(5)}$ Carefully manipulating trays and distracting the patient from the actual work. ${ }^{(6)}$ Acupuncture method was used to control gag reflex. ${ }^{(7)}$ It is used as a safe, quick, inexpensive and relatively non invasive technique. Acupuncture of Chengjiang point is an easy to apply and effective method to reduce gag reflex dur- 
ing transesophageal echocardiography. ${ }^{(8)}$ Acupressure follows the same principle as acupuncture, but the former stimulates the points with finger pressure rather than fine needles and therefore is less invasive technique. ${ }^{(9)}$

The aim of this study is to evaluate the effectiveness of acupressure on Chengjiang point situated in the horizontal mentolabial groove, in controlling of gag reflex in hypersensitive male and female patients attending for prosthetic treatment.

\section{MATERIALS AND METHODS}

Thirty patients were selected from the whole patients attending the prosthetic department of Collage of Dentistry/University of Mousl whom complain from gag reflex during taking of impression. Those patients should fulfill the criteria of patient selection of this study the criteria of patient selection include:

1. They should be partially or completely edentulous.

2. Medically fit. ( with out any medicines).

3. Each patient should score class II or class III using Ellinger classification to hypersensitive palate of gag patient ${ }^{(10)}$.

Ellinger classify sensitive palates as follow:

- Class I there is no response to palpation (excluded from this study). pation.

- Class II minimal response to pal-

- Class III patient makes a violent response to palpation indicate the patient is hypersensitive.

Procedure of classification:

Patient had gag reflex during taking impression was asked to open his mouth and by the usage of a ball ended instrument(stainless steel burnisher, demda, Germany 84.233.27) palpation to the posterior $1 / 3$ of hard palate and the anterior $1 / 3$ of soft palate was done. ${ }^{(10)}$ After that patient who showed class II or class III were included in this study, while patients showed class I were excluded.

Those 30 patients were selected to be 15 male and 15 female. Mean age was 43.5 year.

\section{Procedure of acupressure technique:}

Patients submitted in this study were not informed about the aim of this study. Steps of acupressure technique: ${ }^{(9)}$

1. Mark the Chengjiang point by a felt-tip marker. The Chengjiang point is located on the chin between the Orbicularis Oris muscle and the Mentalis muscle. Fig 1. Chengjiang point is situated in the horizontal mentolabial groove, approximately mid way between the chin and the lower lip.

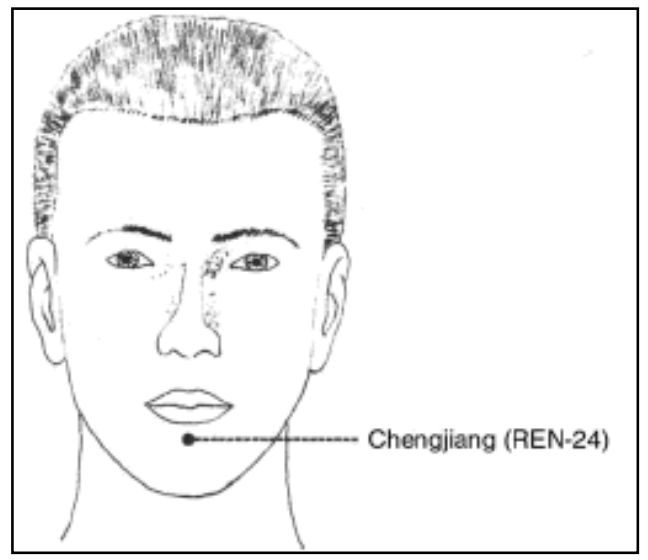

Figure (1): Location of Chengjiang (REN-24) point. ${ }^{(9)}$

2. Apply light finger pressure by the index finger of the right hand of the researcher for about $1 \mathrm{~min}$.

3. Progressively increase the finger pressure (after each min) until the patient feels discomfort and distension. This acupressure procedure needs at least $5 \mathrm{~min}$.

4. At the end of this $5 \mathrm{~min}$ palpation to the patient's palate by the ball ended instrument was repeated by the aid of dental assistant in order to score patient reaction 
to the acupressure technique depending on Ellienger classification. At the same time the pressure on Chengjiang was continuing; because the effect of this technique as anti gagging will stopped by the removal of fingure pressure. ${ }^{(9)}$

The data obtained were statistically analyzed using Mann-Whitney test.

\section{RESULTS}

The control group in this study was the scores of gagged patients before acupressure, while the study group is the scores of same patients after acupressure.

Table (1) revealed the distribution of male patients before acupressure which was as follow: 7 patients scored CL II and 8 patients scored CL III. After acupressure the distribution of scoring became as follow: 4 members of CL II patients scored CL I while the remaining members remained CL II. 2 members of CL III patients became CL I, 4 members became $\mathrm{CL}$ II and the remaining members remained CL III.

Table (1): The relation, number and percentage scores of male patients only before and after acupressure:

\begin{tabular}{lllllll}
\hline & Before acupressure & \multicolumn{4}{c}{ After acupressure } & \multirow{2}{*}{ salue } \\
score & $\mathrm{N}$ & percentage & score & $\mathrm{N}$ & percentage & \\
\hline 2 & 7 & 46.7 & 1 & 4 & 26.7 & 0.73 \\
3 & 8 & 53.3 & 1 & 2 & 13.3 & $0.01^{*}$ \\
\hline
\end{tabular}

1: no gag response.2: patient with minimal gag response.3: patient with violent gag response $\mathrm{N}$ : total no. of patient.*: significant.

Table (2) revealed the distribution of female patients before acupressure was 10 patients scored CL II and 5 patients scored CL III. After acupressure the distribution of scoring became as follow: 5 members of CL II became CL I and the remaining 5 members remained CL II. 3 members of CL III patients scored CL I, 1 patient scored CL II and 1 patient remained CL III.

Table (2): The relation number and percentage of scores of female patients only before and after acupressure.

\begin{tabular}{|c|c|c|c|c|c|c|}
\hline \multirow[b]{2}{*}{ score } & \multicolumn{2}{|c|}{ Before acupressure } & \multicolumn{3}{|c|}{ After acupressure } & \multirow{2}{*}{$P$ value } \\
\hline & $\mathrm{N}$ & Percentage & Score & $\mathrm{N}$ & percentage & \\
\hline 2 & 10 & 66.7 & 1 & 5 & 33.3 & 0.143 \\
\hline 3 & 5 & 33.3 & 1 & 3 & 20 & $0.032 *$ \\
\hline & & & 2 & 1 & 6.7 & \\
\hline
\end{tabular}

1: no gag response.2: patient with minimal gag response.3: patient with violent gag response $\mathrm{N}$ : total no. of patient.*: significant.

Table (3) revealed the distribution of all patients (both male and female) according to their gag scores before and after acupressure.

Acupressure had significant effect on CL III male and CL III female patients $(p<0.01, p<0.03)$ respectively as shown in Table (1) and (2). According to this result, acupressure has also significant effect on
CL III of all patient (male and female) $(p<0.000)$ as shown in Table (3). While acupressure had insignificant effect on CL II male and CL II female patients $(p<0.73$, $p<0.143)$ respectively as shown in Table (1 and 2).when we study CL II male and female patients as a one group $(n=30)$ we found that acupressure had a significant effect $(p<0.008)$ as shown in Table (3). 
Table (3): The relation, number and percentage of all patients (male and female) scores before and after acupressure.

\begin{tabular}{|c|c|c|c|c|c|c|}
\hline \multirow[b]{2}{*}{ score } & \multicolumn{2}{|c|}{ Before acupressure } & \multicolumn{3}{|c|}{ After acupressure } & \multirow{2}{*}{$P$ value } \\
\hline & $\mathrm{N}$ & Percentage & Score & $\mathrm{N}$ & percentage & \\
\hline 2 & 17 & 56.7 & 1 & 9 & 30 & $0.008^{*}$ \\
\hline 3 & 13 & 43.3 & $\begin{array}{l}1 \\
2\end{array}$ & $\begin{array}{l}5 \\
5\end{array}$ & $\begin{array}{l}16.7 \\
16.7\end{array}$ & $0.000 *$ \\
\hline
\end{tabular}

1: no gag response.2: patient with minimal gag response.3: patient with violent gag response $\mathrm{N}$ : total no. of patient.*: significant.

According to the gender of the patients participated in this study there were no significant differences in their response to acupressure between male and female for both gag scores (CL II and CL III) as shown in Table (4).

Table (4): Relation between gender and gag response after acupressure.

\begin{tabular}{ccc}
\hline $\begin{array}{l}\text { Percentage of improve- } \\
\text { ment in male patients }\end{array}$ & $\begin{array}{c}\text { Percentage of improve- } \\
\text { ment in female patients }\end{array}$ & $P$-value \\
\hline 57.1 & 50 & 0.813 \\
---- & --- & \\
--- & -- & 0.435 \\
75 & 80 & \\
---- & --- & \\
\hline
\end{tabular}

\section{DISCUSSION}

The results of the current study showed a significant effect in controlling of gag reflex during prosthetic treatment by the use of acupressure on Chengjiang in both gender. However patients scored class III responded better to acupressure, this can be explained as those patients are hypersensitive and they may had a psychological base line to their gag reflex, in addition acupressure on Chengjiang may had a distraction effect on such patients. One might argue that application of pressure on Chengjiang would cause a person to be distracted from the gag reflex.

There is a search done by Scarborough et $a l^{(11)}$ who used pressure to the center of the palm during dental procedure. They concluded that the application of pressure to the center of the palm would make triggering a gag reflex less likely and move the trigger point of the gag reflex posterior toward the pharyngeal wall.

Some researcher use acupuncture on Chengjiang to control gag reflex. Rösler $e t$ $a l^{(8)}$ compared the effect of acupuncture given in Chengjiang against superficial needling on the chin and an untreated control during a transoeghagal echocardiography. They reported a statistical significant result in the acupuncture group compared with the superficial needling group and the untreated control. Rosted et $a l^{(12)}$ had found that acupuncture of point Chengjiang just before taking an upper alginate impression had a substantial controlling effect on the gag reflex. In addition Mitchell et $a l^{(13)}$ performed a blinded randomized controlled trial of acupuncture on Chengjiang on 45 volunteers to reduce gagging during the insertion of an oral airway. They founded that acupuncture may well suppress the gag reflex significantly during inserting a Berman airway. Finally Fiske and Dickinson ${ }^{(7)}$ studied the role of acupuncture to the antigagging point on the external ear on ten people with an exaggerated gag reflex who had referred to a specialist sedation unit. Eight of ten patients participated in this study, it was possible to control the gag reflex completely and the reflex was partly controlled in the remaining two cases.

However, the innervations of this re- 
gion is unclear as several anatomizes exist. $^{(14)}$

The sensory innervations are transmitted via the Trigeminal nerve and the motor innervations are transmitted via the facial nerve, however, one cannot exclude the participation of fibers from the Transversicolli nerve. The Trigeminal nerve belongs to the soma sensory system, transmitting impulses from mechanoreceptors, thermo receptors in the face and part of the oral mucous membrane, and terminating in the Trigeminal nucleus. The function of the Trigeminal nucleus can be compared to that of the dorsal horn of the spinal column. Thus, fibers from the Trigemonal nucleus continue, like the peripheral nervous system, via the spino thalamic tract to centers in the brain, including the nucleus of the Raphe Magnus. ${ }^{(15)}$ The nucleus of the raphe magnus is the main procedure of 5 -HT in the brain ${ }^{(16)}$ which is metabolized, among other, $\beta$-endorphine, which may have an anti-emetic effect. ${ }^{(17)}$ The gender of the patients participated in this study had no significant effect on percentage of improvement of those gagged patients after acuipressure technique as shown in table (4). The similarity in the structural anatomy in the region of Chengjiang of both genders can display the insignificancy of the differences between them.

\section{CONCLUSION}

We can conclude the following from this study:

1. Acupressure technique is a simple and easy method to control gag reflex.

2. As it is none invasive and effective we can use it before using other invasive techniques like acupuncture or local anesthesia.

\section{REFERENCES}

1. Canny DJ.Tedesco LA.The gagging problem in prosthodontic treatmentpartI: description and causes. Prosthet Dent.1983; 49:601-6.

2. Bassi GS, Humphries GM, Longman LP. The etiology and management of gagging: A review of the literature. Prosthet Dent. 2004; 91:459-467.

3. Bill JL. Dental appliance for patients with a high gag reflex for the use of dental practitioner. Dental Lab J. 2006; 3195): 54-7.

4. Landa JS. Practical full dentures prosthesis. London Kimpton.1954; Pp: 370373.

5. Stewart KL, Rudd KD, Kuebker WA. Clinical removable practical prosthodontic. C.V. Mosby Company.1983; Pp: 529.

6. Friedman S. Diagnosis and treatment planning. Dent North Am. 1977; 21: 246.

7. Fiske J, Dickinson C. The role of acupuncture in controlling the gag reflex using a review ten cases. Br Dent $J$. 2001; 190: 611-613.

8. Rösler A, Otto B, Schreiber-Dietrich D, Steinmetz H, Kessler KR. Singleneedle acupuncture alleviates gag reflex during transesophageal echocardiography: a blinded randomized, controlled pilot trial. J Altern complement Med. 2003; 9: 847-9.

9. Vachiramon A, Wang WC. Acupressure technique to control gag reflex during maxillary impression procedures. J Prosthet Dent. 2002; 88:236.

10.Ellinger CW, Rayson JH, Terry JM, Rahn AO. Synopsis of complet denture. Lea and Febiger; Phladilphia. 1975. Pp: 273.

11.Scarbrough D, Vankurer MB, Hughes S. Altering the gag reflex via palm pressure point. J Am Dent Assoc. 2008; $139 ; 1365-1372$.

12.Rosted P, Bundgaard M, Fiske J, Pedersen AML. The use of acupuncture in controlling the gag reflex in patients requiring an upper impression: an audit.Br Dent J. 2006; Vol 201; Pp:721725 .

13. Mitchell J, Jeffrey S, Lochhead V. Use of acupuncture to reduce gagging during the insertion of an oral airway. Asso Anaes Great Brit Ireland. 2008; 63; 1387-1391.

14.Dean C, Pegington C. Core anatomy for students: The head neck. WB Saunder Company Ltd. 1996; 2; Pp: 109121.

15.Brodal P. The central nervous system structure and function. 3rd ed. USA Oxford University. Cited by Rosted P, Bundgaard M, Fiske J, Pedersen AML. 
The use of acupuncture in controlling the gag reflex in patients requiring an upper impression: an audit.Br Dent J. 2006; Vol 201; Pp: 721-725.

16. Veroux G, Perciavalle V. Foundamental and scientific research in acupuncture. Acupuncture Med Si. 1988; 12-14.
17. Somri M, Waida SJ,Sabo E, Yassain G, Gankin I,Gaitini LA. Acupuncture versus ondansetron in the prevention of post operative vomiting. A study of children undergoing denral surgery. $J$ Anesth. 56: 927. 